\title{
La inconsumada moral de esclavo en la sociedad del rendimiento
}

\author{
The unconsummated slave morality in the performance society
}

\section{Ivonne Natacha Pinzón*}

\footnotetext{
* Docente de Filosofía (Universidad Pedagógica Nacional de Bogotá, Colombia). Estudiante de la Maestría en Ciencia Política y Sociología (FLACSO, Argentina). Temas recientes de investigación: La construcción cinematográfica del enemigo en la Alemania nazi y Representaciones espaciales de inmigrantes latinoamericanos en Ciudad Autónoma de Buenos Aires. $\varangle \cdot$ ivonatty123@gmail.com https://orcid.org/0000-00023037-3639
}

RECIBIDO: 1.8 .2019

ACEPTADO: 24.10 .2019

\section{Resumen}

Byung-Chul Han, en la mayoría de sus obras, describe transformaciones sociales, culturales e ideológicas de la sociedad agraria, disciplinaria y contemporánea, pero al no abordar el campo de la moral deja en cuestión si este cambió o no junto con el paso de cada sociedad. Por tal razón se plantea como hipótesis que, pese a las notables diferencias entre estas tres sociedades, la moral (en términos nietzscheanos, esto es, como noción que se impone y configura colectivamente por un poder establecido) no permutó radicalmente si se piensa que categorías como culpa, mala conciencia e incluso resentimiento aún siguen vigentes en la construcción de subjetividades y modos de relacionarse. En ese horizonte, si bien hay cambios relevantes en la sociedad agraria, disciplinaria y actual, eso no es aplicable al campo de la moral porque en ella se infiere, más bien, una continuidad. La moral de esclavo, tal como es nombrada por Nietzsche, atravesó la carne del ser humano y se le instaló en la conciencia, a tal punto que ni siquiera el paso del tiempo y el cambio en las estructuras sociales han podido erradicarla definitivamente.

Palabras clave: filosofía, sociedad contemporánea, valores morales.

\section{Abstract}

Byung-Chul Han, in most of his works, describes social, cultural and ideological transformations of the agrarian, disciplinary and contemporary societies; however, 
the field of morality is not addressed, leaving in question whether or not it swapped along with the passage of each society. It is hypothesized that despite the notable differences between these three societies, morality (in Nietzschean terms, that is, as a notion imposed and collectively configured by an established power) did not radically permute considering that categories such as guilt, bad conscience, and even resentment are still in force in the construction of subjectivities and modes of relationship. On that horizon, while relevant transformations occur in the agrarian, disciplinary and current society, concerning the field of morality, rather than changes, a continuity is inferred. The slave morality, named as such by Nietzsche, crossed the flesh of the human being and settled down in his conscience, to such an extent that not even the passage of time and the change in social structures have been able to eradicate it definitively.

Keywords: philosophy, contemporary society, moral values.

\section{Distinciones entre la sociedad agraria, disciplinaria y contemporánea}

«El hombre ya no es el hombre encerrado, sino el hombre endeudado». Deleuze, Post-scriptum sobre las sociedades de control, 2006.

Byung-Chul Han (2014) plantea, influido por la teoría del filósofo Michel Foucault, que tanto la sociedad agraria como la sociedad industrializada o disciplinaria se distinguen de la actual sociedad porque el ejercicio del poder permutó: mientras que en la sociedad agraria el poder del soberano amenazaba con la muerte de quien no acataba una orden, en la sociedad disciplinaria el poder se ocupó de la vida, pues los cuerpos se ajustaron a los distintos modos de producción en instituciones donde se coaccionaron y automatizaron los movimientos humanos. Así, «el viejo poderío de la muerte cede ante la "administración de los cuerpos" y la "gestión calculadora de la vida"» (p. 35). En la sociedad disciplinaria el poder adiestró de manera negativa al sujeto a determinadas normas o prohibiciones, de ahí la importancia de un panóptico benthamiano capaz de permitirle a un tercero vigilar, controlar y supervisar el comportamiento de sus súbditos.

Para Han la sociedad contemporánea se distingue de las antes mencionadas en razón de que la actual no necesita del ejercicio negativo del poder, es decir, de prohibiciones o amenazas mortales para crear un sujeto obediente, así como tampoco necesita de un panóptico al estilo benthamiano, porque la actual sociedad está inmersa en constantes prácticas digitales que constituyen el denominado panóptico digital, esto es, un 
eficaz medio de coacción en el que nadie se siente vigilado porque (a diferencia del panóptico de las sociedades disciplinarias) cada sujeto se expone en las redes sociales a fin de controlar y de ser controlado:

El panóptico digital se sirve de la revelación voluntaria de los reclusos. La iluminación propia y la autoexplotación siguen la misma lógica. Se explota la libertad constantemente. En el panóptico digital no existe ese Big Brother que nos extrae informaciones contra nuestra voluntad. Por el contrario, nos revelamos, incluso nos ponemos al desnudo por iniciativa propia. (Han, 2014, p. 62)

La eficacia del panóptico digital radica en el deseo voluntario de exponerse ante los otros. Además, el panóptico digital genera una falsa sensación de libertad que, al contrario del panóptico benthamiano, garantiza la vigilancia desde todos los ángulos. En el panóptico de las sociedades disciplinarias un tercero (patrón, custodio, etcétera) aislaba a los sujetos para vigilar su comportamiento y de este modo garantizar el acato a la norma; en el panóptico digital contemporáneo son los mismos sujetos quienes mediante su espontánea desnudez se vigilan, condicionan y explotan los unos a los otros. En ese sentido, el ejercicio del poder se ejecuta de manera positiva dado que, a diferencia de las sociedades disciplinarias, el poder opera con estímulos y no con amenazas; más aún, el poder emplea el me gusta, el me encanta: «Lisonjea al alma en lugar de sacudirla y paralizarla mediante shocks. La seduce en lugar de oponerse a ella. [...] Con mucha atención toma nota de los anhelos, las necesidades y los deseos, en lugar de "desimpregnarlos"» (p. 57).

El panóptico digital elimina la brecha entre lo público y lo privado, por lo que no es gratuita la proliferación de información concerniente al orden de lo personal en redes sociales. Contemporáneamente, los sujetos exponen sus intimidades e ideales políticos -mediante el presupuesto de la libre expresión- en redes sociales que consideran públicas, pero lo cierto es que esas redes (Facebook, Instagram, Twitter u otras) son privadas y funcionan por medio de la captación de información, que por un lado controlan el comportamiento de los sujetos y por otro lado estimulan la superflua necesidad de adquirir bienes materiales irrelevantes. Esto se observa con el funcionamiento del big data, el cual permite obtener un conocimiento completo de los deseos e inclinaciones de los sujetos para prever el comportamiento humano y mercantilizar hasta el objeto más pueril. En palabras del autor:

El Big Data no solo aparece en la forma de Big Brother, sino también de Big Deal. El Big Data es un gran negocio. Los datos personales se capitalizan y comercializan por completo. Hoy se trata a los hombres y se comercia con ellos como paquetes de datos susceptibles de ser explotados económicamente. Ellos mismos devienen 
mercancía. El Big Brother y el Big Deal se alían. El Estado vigilante y el mercado se fusionan (Han, 2014, p. 98).

Según Han (2013), en La sociedad de la transparencia, los sujetos hoy día se exponen como objetos de publicidad pornográfica, pues «todo está vuelto hacia fuera, descubierto, despojado, desvestido y expuesto. El exceso de exposición hace de todo una mercancía, que "está entregado, desnudo, sin secreto, a la devoración inmediata"» (p. 29). Cuando los sujetos se sienten en la necesidad de expresar todas sus intimidades y de mostrar ante los otros su cuerpo, en realidad se subyugan a la dinámica contemporánea de la mercantilización de su propio ser, pues el mundo contemporáneo hace de la existencia un mercado en el que se exponen, venden, consumen e intercambian intimidades.

En esa medida, Byung-Chul Han denomina a la sociedad contemporánea como sociedad del rendimiento, pues el sujeto del rendimiento ya no necesita de un tercero que lo obligue al trabajo y lo explote; ahora el sujeto se explota e inhibe así mismo: «[...] el actor y la víctima coinciden. La propia explotación es más eficaz que la explotación extraña, pues va acompañada del sentimiento de libertad. El sujeto del rendimiento se somete a una coacción libre, generada por él mismo» (Han, 2013, p. 92). Así, el sujeto contemporáneo opta por trabajar desde casa, medir su desempeño en variables como fracasado-exitoso y hacer de su vida un desfile de apariencias.

La sociedad disciplinaria de Foucault, que consta de hospitales, psiquiátricos, cárceles, cuarteles y fábricas, ya no se corresponde con la sociedad de hoy en día. En su lugar se ha establecido desde hace tiempo otra completamente diferente, a saber: una sociedad de gimnasios, torres de oficinas, bancos, aviones, grandes centros comerciales y laboratorios genéticos. La sociedad del siglo XXI ya no es disciplinaria, sino una sociedad de rendimiento. Tampoco sus habitantes se llaman ya «sujetos de obediencia», sino «sujetos de rendimiento». (Han, 2017, p. 16)

Otros factores que caracterizan la actual sociedad del rendimiento son: desconfianza, carencia de erotismo, cansancio excesivo, eliminación de la otredad y abundancia de enfermedades neurológicas. La desconfianza se hace visible a causa del reclamo constante de transparencia, pues su frecuente exigencia indica que «el fundamento moral de la sociedad se ha hecho frágil, que los valores morales, como la honradez y la lealtad, pierden cada vez más su significación» (Han, 2013, p. 92). En la sociedad contemporánea, por ejemplo, se estimula la interacción en distintas redes para verificar todo aquello que el sujeto diga o haga, porque su palabra perdió valor. Si la actual sociedad 
no estuviera fundamentada en la desconfianza, serían innecesarias las triviales indicaciones que los sujetos hacen de su ubicación o actividad reciente en Facebook, Instagram, WhatsApp, Twitter, etcétera.

Byung-Chul Han (2018), en La agonía del Eros, plantea que el sujeto de rendimiento (dada su condición narcisista) tiende a buscar desesperadamente el éxito, lo que implica compararse y hacer del otro un espejo al que se despoja, justamente, de su otredad, pues «los éxitos llevan consigo una confirmación del uno por el otro. Ahora bien, el otro, despojado de su alteridad, queda degradado a la condición de espejo de uno, al que confirma en su ego» (p. 6). De manera que el sujeto del rendimiento, al hallarse abocado a sí mismo (incluso en el otro como espejo), es propenso a tener enfermedades neurológicas como la depresión, razón por la que Han considera a esta última como la implosión del yo. En otras palabras, para Han la depresión es una enfermedad narcisista propia de esta época-causada por el abandono del otro y la relación exagerada consigo mismo: «El sujeto narcisista-depresivo está agotado y fatigado de sí mismo» (p. 6).

Así, Han contrapone depresión y Eros, porque, mientras la primera sumerge al sujeto en el yo, el segundo (Eros) funciona como desreconocimiento de sí mismo. En esa medida, a la depresión se la combate mediante la interacción con el otro, no como espejo de sí, sino como ser humano capaz de diferenciarse. El problema de lo antes dicho es que la sociedad contemporánea mide toda interacción en términos de rendimiento; por ejemplo:

El amor se positiviza hoy como sexualidad, que está sometida, a su vez, al dictado del rendimiento. El sexo es rendimiento. Y la sensualidad es un capital que hay que aumentar. El cuerpo con su valor de exposición equivale a una mercancía. El otro es sexualizado como objeto excitante. No se puede amar al otro despojado de su alteridad, solo se puede consumir. En ese sentido, el otro ya no es una persona, pues ha sido fragmentado en objetos sexuales parciales. No hay ninguna personalidad sexual. (Han, 2018, p. 13)

En la sociedad del rendimiento se hace del amor mero disfrute, por lo que se cree que este debe generar únicamente sentimientos agradables; se evita así a toda costa la transgresión, el drama, la narración y la tragedia. El amor contemporáneo se reduce al goce y con él se infiere la sexualidad como acto pornográfico en el que se aniquila el Eros, la alteridad: lo distinto. La crisis del Eros radica en la proliferación de lo igual. En ese horizonte, Han habla de una sociedad carente de negatividad, pues la presencia del otro excitaba la fantasía y tensionaba al yo. Hoy día queda la positividad de lo igual: cuerpos lisos, sin imperfecciones, ensimismados y expuestos al rápido consumo.

Llegado a este punto, es posible afirmar: 
a. La autoexplotación que los sujetos llevan a cabo en la sociedad del rendimiento es mucho más eficiente que la explotación ejercida por otro agente, pues quien conoce sus aptitudes se impone más restricciones.

b. En la sociedad del rendimiento imperan las enfermedades neurológicas - depresión, síndrome de desgaste ocupacional (SDO), trastorno límite de la personalidad (TLP), entre otras - porque los sujetos están exhaustos de sí mismos, mientras que en las sociedades agrarias o disciplinarias predominaban las enfermedades inmunológicas - lepra, tifus, viruela, etcétera-, dada la interacción con los demás habitantes de una familia, tribu o comunidad.

c. Las progresivas transformaciones que se dieron en los modos de ejercer el poder y concebir a los otros (como mercancía) y a sí mismo (como productor y consumidor) denotan diferencias radicales respecto a la sociedad agraria, disciplinaria y actual, pero, si se sitúa a la moral como objeto de estudio en el transcurso de esas sociedades, ¿es posible afirmar una continuidad en el comportamiento de los sujetos? La respuesta es sí, véase por qué.

\section{Moralidad y sociedad del rendimiento}

Nietzsche (trad. 1996), en La genealogía de la moral, plantea que el par conceptual bueno y malo procede de la contraposición estamental entre aristócrata y plebeyo. Lo bueno estaba relacionado con los hombres de posición elevada, con el privilegio, y su contrario, malo, aludía a los plebeyos. Así, el aristócrata se adjudicaba la noción de bueno, y el menos privilegiado era considerado malo. Además, quien se identificaba como bueno poseía destrezas en la guerra, por lo que se entiende:

El latín bonus [bueno] en el sentido de 'el guerrero': presuponiendo que yo lleve razón al derivar bonus de un más antiguo duonus (véase bellum $=$ duellum $=$ duenlum, en el que me parece conservado aquel duonus). Bonus sería, por tanto, el varón de la disputa, de la división (duo), el guerrero: es claro, aquello que constituía en la antigua Roma la «bondad» de un varón. (p. 36)

Luego, Nietzsche señala que la idea de bueno y malo sufrió cambios en su significación porque la casta sacerdotal (en su impotencia por saldar deudas con la aristocracia guerrera) transvaloró todas las apreciaciones morales. La venganza de la casta sacerdotal no fue combatir mediante la lucha armada con la aristocracia, sino dar un sentido no estamental a la moral, es decir, lo bueno pasó a relacionarse con la debilidad, el sufrimiento, y lo malo se asoció con la guerra. En palabras del autor: 
¡Los miserables son los buenos; los pobres, los impotentes, los bajos son los únicos buenos; los que sufren, los indigentes, los enfermos, los deformes son también los únicos piadosos, los únicos benditos de Dios, únicamente para ellos existe bienaventuranza, en cambio vosotros, vosotros los nobles y violentos, vosotros sois, por toda la eternidad, los malvados, los crueles, los lascivos, los insaciables, los ateos, y vosotros seréis también eternamente los desventurados, los malditos y condenados...! (Nietzsche, trad. 1996, pp. 39-40)

De ese modo, lo que en la antigüedad se consideraba digno de honor pasó a ser repudiado, pues la transvaloración que llevó a cabo la casta sacerdotal hizo de la representación del poderoso un ser vil y perverso, e hizo del débil y afligido un ser digno de admiración y bondad. Nietzsche indica que la casta sacerdotal por excelencia son los judíos, y que ellos promovieron la herencia moral que posteriormente el cristianismo retomó. De ahí que, también para el cristianismo el hombre bueno es aquel que ante la humillación está dispuesto a poner la otra mejilla, y su antítesis (el hombre malo) se percibe como violento e indómito.

Para Nietzsche (trad. 1996), quienes se apropian de esta percepción sobre la moral son los llamados hombres del resentimiento, pues construyen su felicidad artificialmente y justifican su miseria en nombre de Dios y de la bienaventuranza celestial porque durante la vida terrenal son incapaces de conseguir la felicidad. Según Nietzsche, la rebelión de los esclavos en la moral inicia cuando el resentimiento se vuelve creador y engendra valores, pues ante su incapacidad de acción se refugian en relatos imaginarios en los que, supuestamente, el hombre malo arderá en el infierno por toda la eternidad mientras el hombre bueno se alegrará de tales cosas.

El hombre del resentimiento no es ni franco, ni ingenuo, ni honesto y derecho consigo mismo. Su alma mira de reojo; su espíritu ama los escondrijos, los caminos tortuosos y las puertas falsas, todo lo encubierto le atrae como su mundo, su seguridad, su alivio; entiende de callar, de no olvidar, de aguardar, de empequeñecerse y humillarse transitoriamente. (p. 45)

Lo antes dicho jamás desapareció. La sociedad actual ve con buenos ojos al animal más débil en relación con el más fuerte, a quien - pese a la humillación-se inclina para obedecer; en suma, compadece ${ }^{1}$ al incapaz de ejercer su voluntad de poder y condena la fuerza vital del menos endeble. El imperativo moral de los esclavos se aceptó y pocas veces fue cuestionado; de hecho, los sujetos del rendimiento de la sociedad contemporánea son los que más pagan tributo al lema, pues en nombre de Dios o de una felicidad 
venidera soportan todo tipo de humillaciones con la esperanza de un mañana mejor, de un día más próspero que el anterior, pero ello en realidad nunca llega porque están sujetados a una vida de desecho y consumo constantes. Los sujetos del rendimiento añoran la facilidad y huyen del caos porque su incapacidad es tal que cualquier indicio de negatividad podría atrofiarlos; por eso se tiende a hablarles con eufemismos a fin de no herir su susceptibilidad, pues su debilidad es tal que cualquier indicio de crueldad podría fracturarlos.

Otro factor que no puede descuidarse es el de la culpa: « ¿Se han imaginado, aunque solo sea de lejos, que, por ejemplo, el capital concepto moral culpa (Schuld) procede del muy material concepto tener deudas (Schtdden)?» (Nietzsche, trad. 1996, p. 71). Según este autor, la culpa posee su antecedente en la interacción entre acreedor y deudor, donde este último estaba condicionado a empeñar su cuerpo, su libertad e incluso su cadáver con tal de garantizar al acreedor la seriedad de su deuda. Luego la culpa se introdujo en el campo de la moral —y la cultura — hasta llegar a lacerar la animalidad del ser humano, pues se lo domesticó con prohibiciones y normas sociales hasta el punto de convertirlo en un prisionero que «se desgarraba, se perseguía, se mordía, se roía, se sobresaltaba, se maltrataba impacientemente a sí mismo» (p. 95).

El ser humano (en vista de la negación de su animalidad) no tuvo otra opción que crear una cámara de suplicios denominada mala conciencia, la cual determina nuevas condiciones de existencia en las que se niegan los instintos que exaltan la fuerza, el placer y la fecundidad. La mala conciencia consiste en sentir culpa después de emprender acciones que en su momento causaron placer; esta coarta cualquier ejercicio de vitalidad e inspira —en palabras de Nietzsche- la dolencia más grande, la más siniestra, una dolencia de la que la humanidad no se ha curado hasta hoy.

En ese horizonte, el sujeto del rendimiento que describe Han hereda la culpa, la autotortura, pues durante mucho tiempo los seres humanos han visto con desdén lo humano, esto es, su condición de estar arrojados a un mundo donde la vida se torna compleja porque requiere ver más allá de las cadenas morales, sociales y culturales que imponen los resentidos o, mejor, los minusválidos de la existencia. Quienes niegan la diferencia y hacen de la sexualidad un acto pornográfico con cuerpos lisos y repetitivos, en realidad, menosprecian la diversidad natural y la belleza de los cuerpos. Los resentidos se reducen a la comodidad tras la pantalla y fantasean con un mañana menos tortuoso mientras en el presente niegan la naturaleza trágica del mundo.

Así, la mala conciencia que surgió con la moral explica por qué tanto los sujetos de la sociedad agraria y disciplinaria como los sujetos del rendimiento (de la actual sociedad) tienden a autoexplotarse y maltratarse cada vez que sienten un ligero placer. Cuando los sujetos del rendimiento ingieren alimento, en lugar de saborear la comida, se fijan en las calorías y se obsesionan con eliminar todo rastro de gordura; cuando tie- 
nen sexo, piensan en el rendimiento o la apariencia física y poco disfrutan de las corporeidades; cuando aman, se inhiben por temor a desgarrarse. De ese modo hacen de la vida un pálido suplicio y, ¡como si fuera poco!, estos enfermos de culpa afirman que sus pesares son causados por otros. Así «se experimenta y se busca un bienestar en el fracaso, la atrofia, el dolor, la desventura, lo feo, en la mengua arbitraria, en la negación de sí, en la autoflagelación, en el autosacrificio» (Nietzsche, trad. 1996, p. 137).

La culpa se instala en la conciencia de los sujetos del rendimiento igual o peor que en los sujetos de la sociedad disciplinaria y agraria, porque se trata de una culpa tecnologizada que, además de estandarizar digitalmente un único modo de ser, actuar y sentir, enferma silenciosamente. La actual cultura del rendimiento solo conoce dos estados: funcionar o fracasar, y quien se mide según esa lógica está abocado a un permanente estado de descontento e insatisfacción. Por esta razón la Tierra se convierte en un «astro auténticamente ascético, un rincón lleno de criaturas descontentas, presuntuosas y repugnantes, totalmente incapaces de liberarse de un profundo hastío de sí mismas [...] y que se causan todo el daño que pueden, por el placer de causar daño» (Nietzsche, trad. 1996, p. 136).

A propósito del ideal ascético, Nietzsche expresa que funciona como estratagema en la conservación de la vida, porque afirma (mediante su imperativo de prohibir placeres) salvaguardar la vida, pero ello es una contradicción porque no se puede defender la vida en nombre de la anulación de esta:

Una vida ascética es una autocontradicción: en ella domina un resentimiento sin igual, el resentimiento de un insaciado instinto y voluntad de poder que quisiera enseñorearse, no de algo existente en la vida, sino de la vida misma, de sus más hondas, fuertes, radicales condiciones; en ella se hace un intento de emplear la fuerza para cegar las fuentes de la fuerza; en ella la mirada se vuelve, rencorosa y pérfida, contra el mismo florecimiento fisiológico. (Nietzsche, trad. 1996, p. 137)

Lo antes dicho puede observarse en la actual sociedad porque cuanto más se alude a la salud más se arremete contra la vida. Muestra de ello es la crítica contemporánea que algunos pensadores expresan respecto a la industria farmacéutica, cuya medicación o tratamiento farmacológico, en lugar de curar definitivamente, configura (a través de la dependencia) nuevos modos de padecimiento. Otro ejemplo de negación o reducción de la vida podría vincularse a la proliferación y superposición de lo sano (liso, delgado, frágil) sobre lo distinto, donde el ruido de lo igual acalla la voz de lo diverso; así, el otro como infierno, el otro como amigo, el otro como misterio o deseo desaparecen paulatinamente en la repetición.

En definitiva, se puede inferir que las transiciones y distinciones entre la sociedad agraria, la disciplinaria y la contemporánea no afectaron radicalmente el plano de la 
moral, pues factores como culpa, mala conciencia y resentimiento, propios de la moral de esclavo descrita por Nietzsche, aún siguen vigentes en la sociedad del rendimiento. La conciencia de los sujetos se halla enferma, carente de vitalidad hasta el punto de afectar no solo su subjetividad, sino su interacción con los demás participantes del enjambre digital.

\section{Referencias bibliográficas}

Han, B. C. (2013). La sociedad de la transparencia. Buenos Aires: Herder.

Han, B. C. (2014). Psicopolítica: neoliberalismo y nuevas técnicas de poder. Buenos Aires: Herder.

Han, B. C. (2017). La sociedad del cansancio. (2.a ed. amp.). Buenos Aires: Herder.

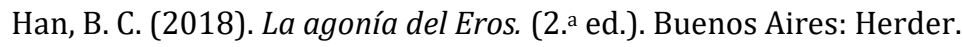

Nietzsche, F. (1996). La genealogía de la moral. (Trad. A. Sánchez Pascual). Madrid: Alianza. 